\title{
El ocaso del contrato: Un estudio desde la doctrina contractual clásica. Problemas en torno a su eficacia*
}

\author{
The Twilight of the Contract: A Study from the Classical Doctrine of the Contract. Problems Around its \\ Effectiveness
}

\author{
John Alberto Tito Añamuro ${ }^{\text {a }}$ \\ Universidad del Norte, Barraquilla, Colombia \\ titoj@uninorte.edu.co \\ ORCID: http://orcid.org/0000-0002-0860-8331
}

DOI: https://doi.org/10.11144/Javeriana.vj139.eodc

Recepción: 24 Mayo 2019

Aceptación: 29 Agosto 2019

Fecha de publicación: 30 Diciembre 2019

\begin{abstract}
Resumen:
Este artículo examina la vigencia del contrato en la realidad jurídica actual. Se parte de la premisa que la categoría del contrato fue diseñada en época de las codificaciones bajo criterios lógico-formales que rozan con la realidad de los hechos o los intercambios en el mercado actual. En este enfoque, se pone en discusión dos líneas de pensamiento jurídico: la que defiende la vigencia del contrato y la que predica la muerte u ocaso del contrato. Bajo el método del análisis histórico, jurídico y filosófico, el artículo se inclina, al final, por la vigencia del contrato, en cuyo contenido son relevantes el estudio de los juristas clásicos del derecho contractual y la fragilidad de quienes defienden los criterios lógico-formales del contrato.
\end{abstract}

Palabras clave: Crisis, contrato, derecho de contratos, consentimiento, validez, eficacia, contrato de adhesión, consumidores.

\section{Abstract:}

This article examines the validity of the contract in the current legal framework It is based on the premise that the contract appeared at the time of encodings under logical and formal criteria that collide with the reality of the facts or the exchanges in the current market. Two lines of legal thought are put into the discussion: one that defends the validity of the contract and the one that preaches the death or decline of the contract. Based on historical, legal, and philosophical analysis, the article is inclined, in the end, for the validity of the contract, taking into account relevant studies of the classical jurists of contract law and the fragility of those who defend the logical-formal criteria of the contract.

Keywords: Crisis, contract, contract law, validity, effectiveness, contract of adherence, consumers.

\section{Introducción}

El contrato fue entronizado como paradigma de intercambio en época de las codificaciones. Ex ante, resultaba inadmisible predicar su unificación en un único modelo obligatorio que descansara sobre la base de un acuerdo de voluntades. Fueron los códigos civiles los que le dieron no solo fuerza obligatoria, sino inmunidad frente a la intervención del Estado.

En aquel contexto, se le exigía al legislador solo dar seguridad de que los negocios se hagan según el diseño libre y espontáneo de los particulares. La fuente, sin duda, hundía sus raíces en el liberalismo económico, en el que el contrato fue el instrumento clave para el libre intercambio de bienes y servicios, sobre la base de una libertad jurídica y una autonomía privada dogmáticamente diseñadas.

Así se había encarcelado al equilibrio o justicia contractual, tras los barrotes de un paradigma conceptual y con la misma determinación que son encarceladas la luz y la materia en la geografía física de un agujero negro. La fuerza de los hechos, no obstante, fragmentó y sigue fragmentando aquella geografía jurídica o modelo

Notas de autor

\footnotetext{
a Autor de correspondencia. Correo electrónico: titoj@uninorte.edu.co
} 
conceptual de la categoría de contrato. Primero fue la formulación de la teoría de la imprevisión, luego la lesión enorme y, entre otros tantos, la adhesión a un contrato previamente redactado por los empresarios.

En la realidad jurídica actual, ese paradigma ilustrado de contrato de plena vigencia en el código civil colombiano, y en particular la autonomía privada, tiene que enfrentar nuevos modificadores contractuales que ponen en tela de juicio su verdadero valor dogmático. Piénsese en el alquiler de vientre, los contratos inteligentes, los contratos electrónicos, entre otros, y en cuál será el impacto de la informática, la manipulación genética incluso la neurociencia en el viejo modelo contractual.

De un lado, la doctrina privatista clásica defiende la vigencia del contrato y, en particular, la vigencia de la autonomía privada sobre la base de la inserción de nuevos límites al acuerdo de voluntades que rebasen aquellos tradicionales de orden público y buenas costumbres, y que buscan, especialmente, un nuevo ajuste del equilibrio del negocio. Por otro lado, otra parte de la doctrina predica el ocaso del contrato sobre la base de la ausencia de voluntad o consentimiento en la nueva generación de contratos, aquellos que son fruto de la masificación, globalización y avance de la ciencia y tecnología.

En esta tesitura, el presente artículo examina el impacto de ambas tendencias en relación con la vigencia o decadencia del contrato bajo los criterios y las herramientas del derecho comparado, con el objetivo de revisar hasta qué punto ha llegado su influencia sobre el derecho colombiano.

\section{Premisa: los cambios y la ruptura del derecho}

Los cambios en la realidad física y en las instituciones sociales no suponen, de cara a la práctica, una novedad. La historia, decía Castán ${ }^{[1]}$, "ha sido siempre cambio y evolución”. Habría que agregar a ello, con vista en la actualidad, que los cambios son nuevos en cantidad y calidad, también dramáticos y drásticos. Se ha puesto en evidencia un proceso de aceleración histórica que viene fragmentando la arquitectura conceptual de las instituciones y áreas de nuestra estructura social. Se vive una ruptura de los moldes o los conceptos sobre los cuales se edificaron las piezas e instituciones sociales, dentro de las cuales se halla localizado el derecho.

Por dondequiera que se vea es posible verificar economías quebradas, tasas de inflación galopantes, abusos de poder, violación de derechos humanos, inmigración, discriminación, corrupción pública y privada, conflictos armados y religiosos, desobediencia social, concentraciones de poder y económicas, mundialización de las economías, entre tantas otras. En palabras de Derrida ${ }^{[2]}$, es posible extraer de su obra La deconstrucción en las fronteras de la filosofía, la idea que estamos presenciando la era de una ruptura de las identidades, es decir, vivimos frente a la fragmentación de las estructuras tradicionales del conocimiento humano y del derecho por inclusión ${ }^{[3]}$.

Piénsese por un momento en los drásticos cambios, por ejemplo, del matrimonio entre personas del mismo sexo, la adopción de menores por estas parejas, el alquiler de vientre, las consecuencias de las inseminaciones in vitro, ni se diga de la manipulación genética, la ruptura de la idea de sociedad con la regulación de las sociedades unipersonales, la cesión de facultades jurisdiccionales a entidades del ejecutivo, las superintendencias, o los nuevos mecanismos de resolución de conflictos y, entre tantos otros supuestos, piénsese en el impacto a futuro de la apertura a un mercado global y los nuevos productos y servicios que se comercializarán fruto de la era digital o informática.

En este sentido, el contenido tradicional de las categorías de la arquitectura del derecho, y del derecho contractual en particular, exigen una revisión: ya creación ex novo o re-creación de normas, proposiciones jurídicas o razonamientos judiciales ajustados a los nuevos hechos. Una revisión no sólo enfocada desde el prisma del derecho, sino también desde otras áreas del conocimiento, convergentes, necesarias y contributivas a la solución de un problema. Marcianò, respecto de esto último, decía "ser expertos en una sola cosa nos hace estúpidos"[4]. 
A raíz de aquellos cambios, ese panorama de ruptura es una muestra de crisis, siempre que por este término se entienda que los instrumentos de solución del ordenamiento no responden ya a los nuevos hechos en términos de eficacia o de justicia o, si se quiere, de mejora del bienestar individual y social.

Para Castán y otros autores ha sido realmente un desafío indagar las causas de ese desorden, desequilibrio o crisis. "El sentido materialista del pensamiento" ${ }^{[5]}$ ha sido para este autor una de las causas de la crisis, donde el capital sustituyó valores propios de la condición humana con la ejecución de doctrinas liberales. Nada alejado de la realidad, y en términos contractuales, Friedman, citado por Diez-Picazo, en esa línea apuntaba a que antes de la I Guerra Mundial hubo una absoluta fidelidad a lo contratado; sin embargo, tras la guerra, la inflación alemana de 1922 y la crisis del 29 abrieron las primeras brechas que sacudieron al contrato de su enclaustramiento formal. La imposibilidad sobrevenida de la prestación se había convertido en una de las herramientas legitimadas desde la doctrina de los jueces para la revisión y la desvinculación contractual ${ }^{[6]}$.

Luego, el hecho que gran parte de la economía se halle en manos de pocas empresas generó consecuencias nocivas. La más notoria de estas, y en términos de impacto, fue el acuerdo o los acuerdos empresariales orientados a limitar los beneficios de la competencia de mercado, con evidente infracción de los derechos de los consumidores, que, bajo la lógica del decimonónico paradigma de contrato, puso en ejecución en el mercado los nocivos carteles, trust y diversas practicas restrictivas de la competencia. Una de cuyas consecuencias en la actualidad es aún un camino por replantear en torno a la aplicación privada del derecho de la competencia ${ }^{[7]}$.

Frente a tales consecuencias, la doctrina jurídica puso esta vez el acento en la revisión del rol del Estado. En efecto, Delitala señalaba frente a ello que "el Estado es una estéril ficción jurídica”, ya que incumple con los deberes que ha asumido hacia la protección del ciudadano ${ }^{[8]}$. Se señala que éste antes de ser ciudadano es hombre con todas las necesidades que conlleva su condición humana ${ }^{[9]}$. En la misma línea de razonamiento, Jemolo afirmaba que "la crisis del Estado es la crisis de las instituciones" ${ }^{[10]}$, y, a su vez, Balladore apuntaba que tal fenómeno engarzaba en la "crisis de la personalidad del Estado"[11].

En esta ola de revisiones jurídicas respecto de la decadencia del derecho, Calamandrei agudizaba su punto de vista yendo más allá, hacia el ámbito de la teleología del derecho, concluyó que tal decadencia era además una muestra de la "crisis de la justicia" ${ }^{[12]}$. Entre otras cosas, aquel fenómeno fue catalogado como crisis de la democracia, cuyo punto de origen quedaba situado en la revolución francesa. En tal orden, Castán, concluyente, afirmaba que "la sociedad fue edificada sobre bases falsas, improvisaciones políticas y sobre la exclusiva preocupación por intereses materiales" ${ }^{\text {[13] }}$.

En suma, los cambios en el derecho ilustrado, esos que ponen en tela de juicio la estructura normativa decimonónica, hunden sus raíces en la heterogeneidad del mercado, esto es, en los nuevos hechos frutos del avance de la ciencia y tecnología, frente a los cuales la doctrina jurídica ha puesto distintos puntos de análisis crítico en el plano científico.

\section{De la luz al ocaso: transformaciones jurídicas del contrato}

Para este examen, una buena premisa de partida es la filosofía del derecho. Radbruch, citado por DiezPicazo, decía que el contrato "después de haber sido considerado creador del Estado (el contrato social), se convertiría en un modesto instrumento del derecho y tal vez en un futuro inmediato solamente en una reliquia

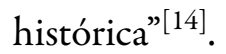

Con base en tal pesimismo institucional, Radbruch hacía transitar el contrato de la luz a la oscuridad, al ocaso. En una lógica análoga a la de Carnelutti, quien afirmaba la muerte del derecho ${ }^{[15]}$, Radbruch predicaba la muerte del contrato. No obstante de tal evidencia, el discurso jurídico no siempre estuvo polarizado así. Entre el iluminismo contractual y su decadencia hubo una larga brecha de orden fáctico. Fueron distintos 
los hechos que pusieron en jaque la época dorada del contrato como categoría formal del derecho privado, cuyo resumen queda anclado en la mutación del contenido del contrato y en la puesta en tela de juicio de la autonomía privada como su esencia jurídica, especialmente a raíz de la masificación de los bienes, productos y servicios, y por ende de la masificación del contrato o puesta en el mercado de los contratos de adhesión.

Todo lo cual reducía el análisis a un punto: el equilibrio de los intereses que encierra la categoría del contrato o, dicho de otro modo, el equilibrio contractual. Ello por cuanto que aquellos hechos vulneraban tal equilibrio, particularmente, a favor de quien tenía una mejor posición jurídica y económica frente al contrato.

Ha sido bajo esta lógica que se ha abierto el discurso acerca de la vigencia o decadencia del contrato. De ambas tendencias, y especialmente de la crítica deconstructiva, se puso el acento en la categoría de la voluntad jurídica, en cuanto a su formación, evolución, vigencia y aplicación bajo el nuevo escenario de derecho contractual.

Justamente, es a esa secuencia, es decir, de la voluntad jurídica, la autonomía privada y la categoría del contrato, la que corresponde examinar a la luz del derecho comparado y la aplicación a derecho nacional, cuando corresponda.

\section{El contrato y el derecho romano}

Desde un punto cero de las cosas, lo primero que habría que decir es que la categoría abstracta de contrato, tal y como lo tiene admitida la doctrina contractual clásica, guarda distancia con la substantia u origen de derecho romano.

Si uno se remonta al viejo ius civile caería en cuenta que el contrato y la obligación fueron creados, ante todo, con el fin de facilitar situaciones de intercambio de orden práctico, dejando, en un segundo plano, lo dogmático o abstracto. Primero, y antes del contrato, fueron las obligaciones. Como señala Blanch ${ }^{[16]}$, fue luego la "jurisprudencia la que recondujo todas las hipótesis existentes de obligaciones a dos fuentes fundamentales: el contrato y el delito" ${ }^{[17]}$. Bajo este criterio, el contrato significaba en su origen una actividad lícita o "acto lícito" y el delito, un "acto ilícito", en orden a que en este último el infractor debía pagar una pena pecuniaria o sufrir una pena física.

En las Institutas ${ }^{[18]}$, Gayo repitió esa bipartición, afirmando que "todas las obligaciones nacen o de acto lícito o de acto ilícito" (3.88); hasta la jurisprudencia clásica, en la que ésta, y el mismo Gayo, pusieron en evidencia obligaciones que no encajaban en la doble fuente de las obligaciones. Entonces se acudió, merced a la genialidad romana, a una tercera fuente. Gayo, en la Res cottidianae ${ }^{[19]}$, una obra posclásica, afirmaba que "las obligaciones o nacen de un contrato o de un delito o, por una especie de derecho propio, de diversas figuras de causas [ex uariis figuris causarum [20] $^{[2]}$. La cuatripartición, llegada a nuestro tiempo, es organizada por los compiladores justinianeos, quienes, como apunta Blanch, crearon un concepto abstracto y único de obligación, nacido "como de contrato" (quasi ex contractu), "como de delito" (quasi ex delito) y en ese sentido las cuatro fuentes de las obligaciones: contratos, delitos, cuasicontratos y cuasidelitos ${ }^{[21]}$.

Se pudo encajar en este esquema general el inasible y problemático pago de lo indebido, el cual en la bipartición fue un verdadero quebradero de cabeza ${ }^{[22]}$. De todo ello, y especialmente de la tercera fuente gayana, se extrae la relevancia de la conventio romana, esto es, el acuerdo productor de obligaciones en el que, según Ulpiano ${ }^{[23]}$, quien cita a Pedio ${ }^{[24]}$, es relevante el consentimiento. Sobre este efecto, Ulpiano menciona que "de tal modo es genérica la palabra convención, que, como sutilmente dice Pedio, no hay ningún contrato, ninguna obligación, que en sí no contenga convención, ya se haga de obra, ya de palabra; porque aun la estipulación, que se hace de palabra, es nula, si no tuviera consentimiento" ${ }^{[25]}$.

Por ello, será el pactum y no el contractus el que sirva de fundamento para la concepción moderna de contrato, especialmente por su flexibilidad y ausencia de tipicidad, a diferencia de la categoría del contractus. 
En tal sentido, el pactum (en términos generales, la conventio) se constituyó en la base ideológica ulterior de la lex privata y del pacta sunt servanda, y en la modernidad del principio de autonomía privada. Tal y como señala Blanch "de pactis conventis atrajo sin duda la atención de los juristas medievales que se decidieron a construir la teoría relativa al contrato, a partir de la idea de pacto y no de la de contrato" ${ }^{\text {[26] }}$, el cual llegó a través de los Glosadores a los códigos ilustrados, previo tratamiento jurídico en textos como el de Tratado de las obligaciones de Pothier y el de Quinto Mucio Escévola, titulado Comentarios al Derecho Civil, entre otros.

En resumen, el pactum tuvo mayor valor e importancia por su flexibilidad que el contractus por su rigurosidad.

En la actualidad, tal ha sido su trascendencia que el Código Civil francés ha revalorado el contenido del pactum, en una nueva categoría, la del acto jurídico. Esta, si bien es ajena a la tradición francesa dado que es más propia de la tradición italiana, ha servido para restructurar la fuente de las obligaciones del derecho francés, esta vez, bajo un esquema tripartito. El artículo 1100, modificado por la Ordenanza de 10 de febrero de 2016, señala a este respecto, que "las obligaciones nacen de los actos jurídicos, de hechos jurídicos o de la autoridad de la ley"[27].

Como se puede ver, bajo este primer análisis no resulta difícil verificar que en el derecho privado romano poca o nula relevancia tuvo la categoría abstracta del principio de la autonomía privada de la voluntad. Como señala Rouhette, citado por López Santamaría, el contrato en Roma se concluía "de conformidad con modelos objetivos reconocidos por el derecho positivo" ${ }^{[28]}$ y no sobre la base de un voluntarismo jurídico, stricto sensu.

\section{Tránsito del status al contractus}

Desde el prisma de las transformaciones jurídicas del contrato, resulta relevante el estudio de uno de los estadios transitorios que ha superado la formulación del contrato moderno, regulado en la mayoría de los códigos civiles del mundo: el tránsito o paso del status al contractus.

Roppo, citado por Diez-Picazo, subraya un punto evolutivo importante: con los códigos civiles, la libertad contractual fue, en el sentido estricto de la palabra, una verdadera libertad por cuanto significó la abolición del vínculo que ataba al individuo a un grupo social ${ }^{[29]}$. Con tal abolición, el sujeto recuperó, en términos de derecho natural, la esfera de su autonomía privada (su libertad); esa que previo a la reglamentación del contractus, estuvo atada a las decisiones de grupo o, lo que es igual, a los criterios e intereses difusos de la posición o status del grupo en la sociedad.

Si bien este paso del status al contractus es una muestra del tránsito de una sociedad primitiva a una forma superior de sociedad, entiéndase por lo primero un régimen patriarcal o uno de obediencia al soberano con vista en el contractus y la autonomía privada del racionalismo jurídico, corresponde subrayar, como señala Diez-Picazo, que la "libertad contractual significó la restitución al individuo, una vez consagrado el principio de igualdad, de la abstracta posibilidad de determinar por sí mismo su propio destino en el mundo del tráfico y de las relaciones jurídicas"[30].

En la actualidad, sin embargo, la regulación de leyes de protección para esa clase especial de los consumidores (en el entendido que el derecho de consumo es un derecho de clase), respecto de los efectos nocivos de los contratos de adhesión, ha puesto en tela de juicio ese tránsito (evolutivo) a una forma superior de sociedad jurídica, por cuanto parece que hay más bien un retorno del contractus al status, es decir, a la lógica de hacer girar los intereses y la protección jurídica en torno al status de los consumidores, pero no en torno a un verdadero examen de los intereses controvertidos dentro del contenido del contrato. Lo que significaría que la justicia contractual moderna privilegia el status de los sujetos por encima de la voluntad reglamentada sobre el objeto del negocio. Yace pues en las normas de protección un margen de inclinación hacia una clase, la de los consumidores, y no a otra, que es la de los empresarios o comerciantes. 


\section{La concepción liberal del contrato y la intervención del Estado}

En cuanto a la concepción liberal del contrato, este de plena vigencia en los códigos civiles, corresponde decir, en primer término, que tal esquema formal, cuyo eje ancla en la voluntad del sujeto, ha venido perdiendo terreno al punto de llegar al de la cosificación del sujeto, esto es, la relevancia del objeto antes que la del sujeto: un tránsito a la facilitación de los intercambios que corre el riesgo de reducir al sujeto a un instrumento de la conclusión de un contrato. No sin antes pasar por el desequilibrio que ocasionan los contratos de adhesión en los intereses contractuales de la parte jurídicamente débil.

De haberse mantenido la aplicación de aquella construcción lógica formal del contrato y de la autonomía privada tal y como se regula en el artículo 1602 del Código Civil, esto es, "todo contrato legalmente celebrado es una ley para los contratantes, y no puede ser invalidado sino por su consentimiento mutuo"[31], que proscribía toda intervención del Estado en la lex privata, los contratos se habrían convertido en una herramienta injusta de maximización de beneficios de aquellos que tienen frente al contrato, no una posición económica fuerte, sino una posición jurídicamente privilegiada.

La libertad de contratar puso en segundo plano la intervención del Estado, sobre la base de un exacerbado voluntarismo jurídico y liberalismo económico. Se logró homologar lo contractual con lo justo. Bajo el principio de identidad, ese extraído de la lógica formal, todo lo encerrado en las cuatro esquinas de un contrato era considerado justo. Arrubla, en nuestro entorno, afirmaba que si el Estado se extendía a la órbita privada, se consideraba tiránico ${ }^{[32]}$.

Los únicos límites al imperium del contrato eran el orden público y las buenas costumbres. Con lo cual, cualquier intervención del legislador a la lex privata rompía el equilibrio formal del negocio y, por consiguiente, era considerada injusta.

Bajo esta quasi sacralización de la autonomía privada y del contrato, la lógica de los cambios en el mercado fue mutando la defensa de esas categorías abstractas. Gradualmente, aquellos esquemas formales pusieron en evidencia fisuras que terminaron por liberar el equilibrio material del contrato, quedando atrapado en las estructuras abstractas de los códigos civiles, y facilitando una nueva regulación que privilegia los intereses colectivos o difusos por encima de los individuales. Así, también es posible colegir de la Ley 1480 de 2011 que busca, además de la protección, garantía y libre ejercicio de los derechos de los consumidores, un retorno al equilibrio material, a través de la proscripción del desequilibrio injustificado en perjuicio del consumidor ${ }^{[33]}$.

Si el contrato, según se dijo antes, tuvo, en su origen ilustrado, inmunidad frente a la intervención del Estado, la imposibilidad sobrevenida de la prestación rompió con ella, sacando a la luz la primera brecha o fragmentación de contenido contractual. El juez se hallaba legitimado para modificar la fuerza obligatoria de los términos privados del contrato e incluso liberar a las partes de sus obligaciones en supuestos de realización de acontecimientos económicos extraordinarios e imprevisibles.

Friedmann, citado por Diez-Picazo, en efecto, subraya la irrupción del juez en la privacidad del contrato, a través de la categoría de la imposibilidad sobrevenida, y la regulación en los textos legales, como único medio para liberarse de las obligaciones contractuales ${ }^{[34]}$.

Justamente, a raíz de la teorización de esta irrupción en la esfera privada del contrato, Francia, en 1916, instituyó la teoría de la imprevisión con base en el gas de Burdeos, un caso paradigmático de orden administrativo; el Reino Unido, a través de la doctrina de la frustración del fin del contrato; Alemania, con la doctrina de la presuposición y el de la base del negocio jurídico y, entre otros, Italia, mediante la teoría de la excesiva onerosidad. Como bien resume Fernández, quien, en esta misma línea, señala que todas estas posiciones nacen, como de un crisol, de la vieja categoría romana de la cláusula rebus sic stantibus, que, para el autor, serían equivalentes en tanto tratan de dar respuesta al mismo problema, este que suscita la alteración sobrevenida de las circunstancias contractuales ${ }^{[35]}$. 
En términos de derecho romano, la cláusula rebus se habría constituido en una excepción a la regla pacta sunt servanda, sobre la base de la ralentización o ruptura de la categoría de la lex privata. En esta misma línea de cosas, en la revisión de la función práctica del contrato ilustrado, no resulta posible ver las consecuencias que, en terreno empírico, han tenido los convenios colectivos, los contratos forzosos y los contratos de adhesión, que podrían considerarse como los principales modificadores de la categoría liberal de contrato.

De acuerdo con esto, resulta pacífica la posición de poner el acento en la relevancia del contrato de adhesión, dado que modificó los dos escenarios del contrato: el dogmático y el empírico. En el primero, puso en jaque la vigencia del consentimiento, substantia del contrato, por cuanto que al adherente, frente a un contrato preredactado, solo le quedaba la posibilidad de aceptarlo o rechazarlo en bloque o, como dicen los ingleses, take it or leave it, en cuyo caso, tras esa falta de consentimiento o autonomía de voluntad, desaparecía toda discusión negocial. Habría, más bien, como señala Clavería, una imposición y no negociación del contrato ${ }^{[36]}$. En mi opinión, es, en definitiva, un sometimiento y no consentimiento.

Y, en cuanto a lo segundo, en clave de transformaciones jurídicas, los contratos en el mercado aumentaron cuantitativamente como lógica reacción a la masificación de la producción. Diez-Picazo, en efecto, a este respecto afirma que "la mayor parte de los contratos que gobiernan nuestra vida diaria son absolutamente uniformes: los trasportes, los seguros, los servicios bancarios, los suministros de electricidad o de gas y tantas otras actividades" ${ }^{\text {[37] }}$. En ambos casos, esto es, el dogmático y el empírico, ha sido necesaria la intervención del Estado en la esfera privada de las partes, particularmente a través del llamado control de cláusulas de incorporación y de contenido ${ }^{[38]}$.

Tales remedios han sido recogidos en nuestro sistema, según se dijo antes, en la Ley 1480 de 2011, bajo las categorías de cláusulas abusivas e ineficacia de pleno derecho, como se colige de los artículos 42 y 43 de la ley que, a estos efectos, señala "son cláusulas abusivas aquellas que producen un desequilibrio injustificado en perjuicio del consumidor (...), los productores y proveedores no podrán incluir cláusulas en los contratos celebrados con los consumidores" y, en este sentido, "son ineficaces de pleno derecho las cláusulas que limiten la responsabilidad del productor o proveedor de las obligaciones que por ley les corresponden (...)" ${ }^{[39]}$ y un largo etcétera, que la doctrina ha denominado la lista negra, en referencia a las cláusulas abusivas.

Como se puede observar, es evidente la intervención del legislador y del juez en los asuntos privados de las partes. El orden público y las buenas costumbres han dejado de ser los únicos límites de la autonomía privada. El nuevo orden normativo que privilegia la protección del equilibrio material mantiene constante y vigente la voluntad jurídica de celebrar o concluir un contrato, pero la limita en cuanto a la configuración lesiva del negocio, a través de la sanción de ineficacia de aquellas cláusulas nocivas, manteniendo, según se dijo antes, la vigencia del contrato. Además, en tal objetivo se han multiplicado las normas imperativas y modificado las dispositivas, regulando derechos colectivos básicos y buscando, en definitiva, una justicia material del contrato.

En tal orden de cosas, la crisis, decadencia u ocaso es predicable del contrato ilustrado, así como es predicable la liberación del equilibrio material, merced a la intervención del legislador y del juez en aplicación del vigente orden correctivo. En este contexto, es también, en mi opinión, una constante frente a los diferentes cambios examinados, la vigencia del consentimiento o, si se quiere, la voluntad jurídica de querer un negocio. En este sentido, señalan las sentencias de casación civil de la Corte Suprema, de 15 de diciembre de 1970 y 29 de agosto de $1980^{[40]}$, en un caso de contratos de adhesión, que mientras el cliente pueda rechazar la oferta, su voluntad jurídica actúa a tal punto que al acogerla presta voluntariamente su consentimiento y, de otro lado, que no hay duda que mediante la adhesión se configura un verdadero contrato.

Como colofón de este bloque de análisis, se ha considerado examinar brevemente, y sin perder el rigor del caso, los vicios del consentimiento y la interpretación subjetiva del contrato. Así, partimos de la afirmación de que ambas categorías, y la institución misma del contrato, hunden sus raíces en la voluntad. Como señala Diez- 
Picazo, "se podía haber hablado de libertad o de poder de decisión, pero el acento se colocó en la voluntad: acuerdo de voluntades, autonomía de la voluntad, etc." ${ }^{[41]}$.

Con base en esto, el voluntarismo jurídico instituyó la ideología sobre la cual se erigió el sistema contractual, que situó el "dogma de la voluntad" o, lo que es igual, "la perfecta voluntad" en la base del sistema. Justamente, el efecto de esto es que no resulta fácil explicar en la actualidad por qué los vicios del consentimiento en el código civil se reducen a tres: error, fuerza y dolo ${ }^{[42]}$ ( $c f r$. art. 1508), cuando en términos de una "perfecta voluntad", debería ampliarse a otros supuestos permisibles de verificación de una verdadera vinculación volitiva: no deberían encerrarse los límites del consentimiento en solo tres supuestos.

Como señala Diez-Picazo resulta inexplicable que, por un lado, solo el error sustancial invalide el contrato y no los otros errores que, al producir un conocimiento distorsionado, impiden la verdadera volición y, por otro lado, resulta imposible saber por qué se adoptan criterios de interpretación objetiva como la interpretación usual, la interpretación contra estipulatorem o la interpretación que tienda a conservar el negocio y a dotarle de mayor eficacia, porque si el contrato es voluntad, solo los llamados criterios de interpretación subjetiva deberían mantenerse ${ }^{[43]}$.

No cabe duda que la matematización ilustrada del contrato ha encarcelado la libertad de contratar y la voluntad dentro de aquel decimonónico texto abstracto de los códigos. En las manos de esa geografía jurídica, vigente en los códigos, ha acabado de explotar peligrosamente el contenido, los límites y la función del contrato.

\section{La vigencia del consentimiento en la realidad jurídica actual}

Justamente, en el tráfico jurídico actual reina la facilitación del contrato. Se ha ralentizado el rigor de los límites o control jurídico de la validez del contrato. De acuerdo con los Principios de Derecho Contractual Europeo (PECL), la conclusión válida de un contrato no pende de los hilos de la categoría tradicional de los requisitos esenciales; no está sujeta a condición alguna, salvo a la intención o voluntad de obligarse. En efecto, el artículo 2101 señala que "el contrato se perfecciona, sin necesidad de ninguna condición, cuando las partes tienen la intención de obligarse legalmente y alcanzan un acuerdo suficiente" ${ }^{[44]}$ y por intención el artículo 2102 entiende que "la voluntad de una parte de obligarse por contrato se determinará a partir de sus declaraciones o su conducta, tal y como éstas fueron razonablemente entendidas por la otra parte" ${ }^{\text {[45] }}$. De donde se evidencia que el requisito de la causa y el del objeto han perdido el control jurídico que los codigos civiles tradicionales le habían otorgado. Si se mira bien, esta variable de descausalización arrastra consigo la tradición de la causa jurídica al ámbito de la controversia, especialmente en países en los que la causa es un pilar del derecho de contratos ${ }^{[46]}$.

Si se piensa en la validez del contrato de alquiler de vientre ${ }^{[47]}$ o en los algoritmos de consenso de los smart contracts (contratos inteligentes) ${ }^{[48]}$, y se agrega a ello lo que ya se dijo de la causa, tal parece que con el operador jurídico se ingresa a un escenario impenetrable, desconocido, donde cualquier examen parece difuminarse. No así, cuando menos a priori, si de aquellas variables del contrato o, propiamente de su función y eficacia, se deduce que en puridad no se corresponden con la legislación y comprensión tradicionales. Se ha roto el contrato. Se ha fragmentado la arquitectura conceptual in extremis racional del contrato, y viene poniéndose de manifiesto el viejo instrumento del consentimiento o solus consensus obligat, quien con mayor libertad por amplificación de sus límites (a los de orden público) vuelve a ser una constante, flexible y necesaria de nuevas fórmulas de intercambio contractual.

No es de ficción la invasión de la era digital en el derecho. No lo es tampoco la teoría cuántica en las ciencias causales, ni lo es la inteligencia artificial en el campo del contrato. En tal sentido, hoy, desde la neurociencia, no debe parecer extraño que se asuma, con riesgo a revisión, que el cerebro es quien toma decisiones y no el "sujeto de derecho", ese sujeto tantas veces manido en la teoría jurídica. Ciertamente, ello 
conduciría a una re-clasificación de la información jurídica. En materia penal, por ejemplo, en términos de inimputabilidad, una conducta podría estar exenta de responsabilidad si esta deriva, no de la voluntad del sujeto, sino de una decisión predeterminada por el cerebro. Y aunque los estudios científicos indican que si bien no hay una variante genética que determine de manera absoluta la realización de una conducta, en el estado actual de conocimientos la posesión de más de una variante asocia el riesgo estadístico de manifestar un comportamiento determinado ${ }^{[49]}$.

Con base en ello y todo lo que se ha dicho en estas líneas, hasta los más cáusticos críticos de hoy estarán de acuerdo en que el impacto de los nuevos hechos, una constante del derecho, ha modificado la función y eficacia del decimonónico contrato codificado. Con lo cual, esta revisión está lejos de ser una herejía al consensus, substantia del contrato. Si bien el esquema de contrato ha perdido eficacia, no lo ha hecho, cuando menos hasta el estado de conocimientos actual, el viejo consensus solus obligat romano.

\section{Sobre la crisis del derecho}

No todos los juristas admiten que el derecho haya entrado en fase crítica a raíz de los nuevos hechos de la vida social. Algunos apuntan que el derecho está más bien en fase fisiológica, formativa o evolutiva y no estrictamente patológica. En efecto, frente al punto de vista de que el derecho no está en fase de decadencia, sino de nacimiento y formación, Delitala es determinante cuando afirma que "los continuos procesos de transformación y renovación que se desarrolla en el ámbito del Derecho no son signos de crisis sino de vitalidad, por eso no estamos en el campo de la patología, sino de la fisiología" ${ }^{[50]}$. Así las cosas, es posible colegir que nos hallamos más bien con un problema de aplicación de la ciencia, de la técnica, de las reglas y de los instrumentos del derecho. Carnelutti es, en esta lógica, un extremo o, dicho de otro modo, el filo de su crítica engarza el pesimismo jurídico, esto es, que el derecho se encuentra en estado patológico, siendo su tendencia la muerte, la desaparición o la muerte propiamente del derecho ${ }^{[51]}$.

En cambio, Ripert defiende la concepción dinámica del derecho, ya no pesimista, según los incisivos filos de la navaja de Carnelutti, señalando que el derecho está en continua evolución a causa de dos grandes fuerzas que interactúan entre sí: las fuerzas conservadoras y las fuerzas reivindicadoras. Las primeras mantienen el orden jurídico existente y las segundas la fuerza de los agremiados, trabajadores e ideólogos que cuando triunfan son creadoras de un nuevo derecho ${ }^{[52]}$.

Ravá, no obstante, crítico y agudo, señala que ello constituye un "modo difuso de ver las cosas, pues el cambio no es una continua evolución, sino que procede por contrastes; la evolución del derecho no siempre

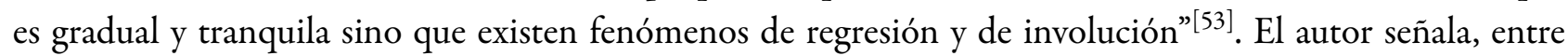
otras cosas, que la crisis se manifiesta cuando la estructura social que ha experimentado cambios profundos y radicales, las viejas fórmulas jurídicas se convierten en instrumento de injusticia ${ }^{[54]}$.

Así las cosas, la crisis llega a ser un problema de adaptación de las normas jurídicas existentes a las nuevas exigencias. Como señalaba Jemolo "la dificultad está en enmarcar en algunos viejos cuadros una serie de nuevas instituciones, la necesidad de introducir en los cuadros del derecho romano, constituye una pequeña crisis" [55].

Crisis o evolución parece ser la paradoja que ha marcado nuestra actual organización social; sin embargo, debe destacarse el valor de la justicia como una unidad. Una de las opciones abordadas por Ripert, justamente, tiene que ver con el punto de vista teleológico, vale decir, la finalidad del derecho. El autor menciona que "el derecho tiene por objeto hacer reinar el orden en la sociedad, el verdadero progreso del derecho consiste en dar nuevas reglas, y sólo con el fin de asegurar un orden mejor" ${ }^{[56]}$.

Este punto de vista teleológico fue objetado, por cuanto la finalidad del derecho no es estabilizadora o conservadora, no propende llegar a una meta de paz social perpetua; sino que, el derecho debe entenderse en sentido de la "función que cumple". En este sentido, Delitala sostiene que el derecho como función es la 
garantía de un ordenado desarrollo de la vida social y por ello la crisis sólo puede superarse y resolver cuando

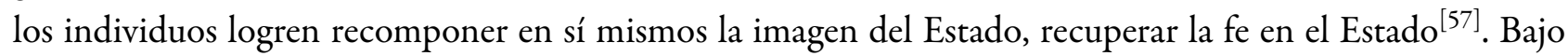
esta lógica, el autor cuestiona la tesis finalista de Ripert en el sentido que sostenerlo significaría "soñar con un Estado perfecto" ${ }^{[58]}$. Y el Estado perfecto \#señala el autor\# es una ilusión mágica porque el hombre por su naturaleza es llevado a hacer coincidir la justicia con su utilidad. El autor concluye, objetando aquel criterio naturalista, señalando que "el derecho natural ha sido concebido en el siglo de las luces, es bueno para la ciudad de utopía pero la ciudad de utopía no pertenece a la tierra"[59].

Con todo, bajo estos criterios es defendible la posición de que el derecho se ubica en su misma funcionalidad, es decir, en su fase fisiológica, pues es signo de vitalidad y no de crisis, por tanto, inmerso en el terreno de la fisiología y no de la patología del derecho.

Con criterio más específico, quizá científico, Calamandrei secciona aquel bloque de conocimiento. El autor prefiere ubicar estas transformaciones en periodos transitivos, que llama losperiodos de crisis de legalidad, el que se manifiesta en los jueces cuando se ven constreñidos a aplicar leyes que ya no corresponden a la conciencia social que es donde se ubica el peligro de la legalidad ${ }^{[60]}$. Pero, el autor sentencia que no es admisible hablar de la muerte del derecho sino del nacimiento del derecho ${ }^{[61]}$. Ravá, en la misma dirección, manifiesta que "la adaptación de normas jurídicas a las nuevas exigencias ya no tiene lugar el resolver las dificultades invocando el retorno a ordenamientos ya superados, acentúa la crisis, porque la historia no vuelve atrás" ${ }^{[62]}$. El autor menciona además que "la crisis no puede ser seguida en su desarrollo por una gradual evolución jurídica porque las modificaciones que producen las leyes son un obstáculo para el derecho, y es en este sentido que se puede hablar de crisis del derecho" ${ }^{\text {"63] }}$.

La muerte del derecho es la posición extrema del fenómeno. Ya lo dijimos, es planteado por Carnelutti, señalando, entre otras cosas, que la crisis es algo más grave, es el fracaso de la doble función del derecho, la certeza y la justicia, que por la multiplicación de las leyes el ciudadano ha perdido la capacidad de conocerlas, la publicación como condición imperativa de la ley ha pasado a ser de presunción a ficción ${ }^{[64]}$.

He ahí el peligro de certeza asociado al peligro de justicia. Bajo este criterio el derecho sale de la fisiología e ingresa en el terreno de la patología cuya prospección es su desaparición o muerte, en palabras de Carnelutti.

En suma, estas brillantes apreciaciones acerca de la justicia, certeza, libertad, seguridad jurídica y legalidad sirven como cristales que muestran la continua polémica sobre la naturaleza del derecho. Con todo, se admite que la justicia es el valor supremo, relevante en grado e interés, en el que alcanzan sentido los demás valores del derecho.

Por último, en torno a la crisis del derecho civil, los civilistas han acogido la tesis de la relatividad de los derechos. Los romanistas con más responsabilidad han soportado el peso de revisión, pues el derecho moderno ha vuelto los ojos hacia aquella necesidad. Don Alvaro d'Ors, eminente romanista, señalaba, respecto de la unificación del derecho privado europeo, que de nuevo el derecho romano se presenta en la palestra de la problemática jurídica más viva y con las más altas pretensiones de dar todavía su gran lección al mundo ${ }^{[65]}$.

Delitala abordó el tema, desde el derecho de propiedad y el derecho de libertad, ambos con una unidad de origen en el Estado. En cuanto a lo primero, la crisis se presentaba a raíz de los problemas de restricción de la propiedad según las circunstancias de cada pueblo y momento. En cuanto a lo segundo, aquella se manifestaba a raíz de la restricción del principio de libertad ${ }^{[66]}$.

Con todo, si se quisiera hacer una valoración de las transformaciones relevantes fruto de los cambios, crisis o evolución del derecho, estas serían:

a) La intervención del Estado en el juego de la contratación.

b) El desplazamiento del derecho privado por el derecho público, como consecuencia del intervencionismo del Estado, y 
c) La disgregación que sufre el derecho civil de sus importantes materias: mercantil, navegación, aéreo, agrario y laboral

Un cambio añadido y actual es el efecto de la privatización de las empresas del Estado, que trae como correlato el fenómeno de la publificación de ciertas actividades y servicios que es consecuencia de la política de liberalización del Estado a través del uso del instrumento o título de intervención, lo que, en efecto, podría considerarse como una inmersión del derecho público en el derecho privado.

El derecho civil, dadas estas circunstancias, no implica que se encuentre en una fase de destrucción, desaparición o muerte como diría Carnelutti. Afortunadamente, a pesar de los cambios los pilares sobre los que se erigieron sus instituciones se mantienen sólidos como son: la estabilidad de la familia, el valor del derecho subjetivo, la vigencia de la propiedad individual, la fuerza obligatoria de contrato, la responsabilidad por culpa, la sucesión hereditaria y otras. Si se miran bien las cosas, la expresión de crisis del derecho civil se ha extendido peligrosamente, pero en esencia el derecho civil se ha mantenido firme, a pesar de las vicisitudes, mostrando continuidad y universalidad.

Persisten valores permanentes; entre ellos está el respeto a la persona, simbolizado por la unidad y la estabilidad de la organización jurídica. Una muestra de ello son las nuevas tendencias hacia la unificación del derecho comercial y del derecho civil, agregando a ello el derecho de consumo, y otras en el papel que la historia les ha otorgado a los romanistas al explorar los fenómenos actuales en la raíz del derecho romano. Así, el derecho romano de ser estudio de una rama de la filología clásica, ajena a la vida jurídica, vuelve irónicamente producto del exacerbado uso de la ley que desde el ángulo visual romano es su antítesis: ius y lex.

Por último, si bien, el derecho privado, siendo como es, constituye la parte más conservadora del sistema jurídico y soporta la crisis con firmeza; se le ha reducido y limitado a ciertas zonas por efecto de los modificadores sociales, económicos, entre otros, pero particularmente por la tecnología e informática. Con todo, será difícilmente descalificado en su esencia.

\section{Conclusiones}

El contrato y la autonomía privada son categorías fruto de la ley y, particularmente, de los postulados del voluntarismo jurídico y liberalismo económico, en cuyo contexto, y en época de la ilustración, fueron privilegiados con inmunidad frente a la intervención del Estado.

El impacto de los hechos ha terminado por liberar el equilibrio material del contrato de manos de aquella construcción lógico formal del contrato y de la voluntad jurídica. En tal orden, la intervención del legislador y del juez ha sido decisiva para reestablecer el equilibrio del negocio. Se ha logrado al mantener la vigencia de la voluntad jurídica y prohibir el nocivo desequilibrio injustificado con el control de cláusulas de incorporación y de contenido, la reglamentación de normas imperativas y adecuación de las dispositivas.

Se puede afirmar que, tras el examen de la construcción, evolución e impacto del contrato en la realidad jurídica, el ocaso es predicable del contrato ilustrado, debido a que ya no tiene la libertad y el imperium de época de las codificaciones. Ha habido, en este sentido, una inversión de la valoración del contenido negocial. Con las correcciones normativas y de equidad, en la actualidad se privilegian los intereses difusos o colectivos por sobre los individuales. El ocaso no corresponde, entonces, al consentimiento, sino al contrato de la ilustración, del iluminismo jurídico de los códigos civiles vigentes.

Con todo lo cual, tal y como se ha puesto en evidencia en este artículo, no resulta predicable inclinarse por la patología del derecho y, en concreto, del contrato, sino más bien por su dinámica y fisiología en un ámbito de continua transformación social y jurídica. 


\section{Bibliografía}

Adolfo Ravà, Crisis del derecho y crisis mundial, en La crisis del derecho, 101-151 (Georges Ripert ed., Ed. Jurídicas Europa América, 1961).

Adolfo Wegmann Stockebrand, En torno al carácter (cuasi) contractual de la solutio indebiti en las Instituciones de Gayo, Revista Estudios Histórico-Jurídicos, n. ${ }^{\circ} 39,85-110$ (2017). http://dx.doi.org/10.4067/S0716-545520170001 00085.

Alejandro Guzmán Brito, Causa del contrato y causa de la obligación en la dogmática de los juristas romanos, medievales y modernos y en la codificación europea y americana, Revista Estudios Histórico-Jurídicos, n. 23, 209-367 (2001). https://doi.org/10.4151/ISSN.07176260-Num.23-Fulltext.337

Álvaro d'Ors, Derecho y sentido común: siete lecciones de derecho natural como límite del derecho positivo, Ed. Cuadernos Civitas (3a. ed., 2001).

Antonio Silva Sánchez, Origen del concepto actual de contrato en el marco del derecho privado comparado. Situaciones especiales del contrato de arrendamiento (locatio conductio) en el derecho romano y en el derecho privado comparado, Ars Iuris, n. ${ }^{\circ} 39,181-208$ (2008).

Arturo Jemolo, La crisis del Estado moderno, en La crisis del derecho, 183-265 (Georges Ripert ed., Ed. Jurídicas Europa América, 1961).

Beatriz Romero Flores, Las neurociencias frente a la función de la pena, LXVIII Anuario de Derecho Penal y Ciencias Penales, n. ${ }^{\circ}$ 1, 335-357 (2015). https://www.boe.es/publicaciones/anuarios_derecho/articulo.php?id=ANU-P $-2015-10033500357$

Carlos Andrés Uribe Piedrahita, Los compromisos - settlements - en América Latina y las consecuencias sobre la aplicación privada del derecho de la competencia. Un camino por replantear, en La aplicación privada del Derecho de la Competencia, 803-818 (Luis Antonio Velasco San Pedro et. al. eds., 2011).

Código Civil Colombiano [CCC]. Ley 57 de 1887. Arts. 1602, 1508. 15 de abril de 1887 (Colombia).

Código Civil Francés [CCFr]. Ley del 21 de marzo de 1804. Art. 1100. 21 de marzo de 1804 (Francia).

Comisión de Derecho Europeo de los Contratos, Principios Europeos de Derecho de Contratos, PECL (2000). http: //campus.usal.es/ derinfo/Material/LegOblContr/PECL\%20I+II.pdf

Corte Constitucional de Colombia. Sentencia C-807 de 2002 (M. P. Jaime Araujo Rentería; 3 de octubre de 2002).

Corte Suprema de Justicia, Sala de Casación Civil, Sentencia aprobada según acta n. ${ }^{\circ} 112$ de $1^{\circ}$ de diciembre de 1970. Gaceta Judicial, Tomo CXXXVI. (M. P. Dr. Guillermo Ospina Fernández; 15 de diciembre de 1970).

Corte Suprema de Justicia, Sala de Casación Civil. Sentencia aprobada según Gaceta Judicial, Tomo CLXVI, Número 2407. (M. P. Humberto Marcia Ballén; 29 de agosto de 1980).

Encarnación Fernández Ruiz-Gálvez, Rebus sic stantibus y crisis económica. Orden público económico versus especulación, XXXIII Anuario de Filosofía del Derecho, 63-98 (2017).

Francesco Carnelutti, La muerte del derecho, en La crisis del derecho, 339-362 (Georges Ripert ed., Ed. Jurídicas Europa América, 1961).

Georges Ripert, Evolución y progreso del derecho, en La crisis del derecho, 13-31 (Georges Ripert ed., Ed. Jurídicas Europa América, 1961).

Giacomo Delitala, La crisis del derecho en la sociedad contemporánea, en La crisis del derecho, 153-182 (Georges Ripert ed., Ed. Jurídicas Europa América, 1961).

Giorgio Balladore, La crisis de la personalidad del Estado, en La crisis del derecho, 267-297 (Georges Ripert ed., Ed. Jurídicas Europa América, 1961).

Jacques Derrida, La deconstrucción en las fronteras de la filosofía, Ed. Paidós,13-22 (1989).

Jaime Arrubla Paucar, Contratos mercantiles, Ed. Legis (3a ed., 1986)

Javier Ibáñez, Blockchain: Primeras cuestiones en el ordenamiento español, Ed. Dykinson (2018). 
Jordi Pueyo, Entrevista a Antonio Marcianò. El físico que reivindica el Renacimiento: "Ser expertos en una sola cosa nos hace estúpidos”. El País. 14 de junio de 2019. https://elpais.com/elpais/2019/06/09/ciencia/1560093111 _074613.html

Jorge López Santamaría, Los contratos: parte general, Ed. Jurídica de Chile (1986).

José Castán, Crisis mundial y crisis del derecho, Editorial Reus, 11 (1961).

Juan Blanch, Algunas reflexiones en torno al concepto romano y moderno de contrato, CEU Ediciones (2017).

Juan Cruz \& Laura Castro, La omisión legislativa en materia de contrato de alquiler de vientre materno en Colombia y consecuencias jurídicas, 6 Revista Criterio Jurídico Garantista, n. ${ }^{\circ}$ 11, 110-125 (2014). http://dx.doi.org/10.26 $564 / 21453381.443$

La Instituta de Gayo, Descubierta recientemente en un palimpsecto de la Biblioteca Capitular de Verona, traducida por primera vez al castellano (1845).

Ley 1480 de 2011. Por medio de la cual se expide el Estatuto del Consumidor y se dictan otras disposiciones. 12 de octubre de 2011. D.O. n. ${ }^{\circ} 48.220$.

Luis Clavería, La progresiva degradación de nuestro ordenamiento en materia de cláusulas contractuales abusivas, Revista Aranzadi Doctrinal, n. ${ }^{\circ}$ 2, 29-42 (2014).

Luis Diez-Picazo y Ponce de León, Contrato y Libertad Contractual. THĒMIS-Revista de Derecho, n. ${ }^{\circ}$ 49, 7-14 (2004). http://revistas.pucp.edu.pe/index.php/themis/article/view/8545

Mariana Bernal, La transformación de la causa en el derecho de contratos francés, 55 Vniversitas, n. ${ }^{\circ} 111,227-243$ (2006). https://revistas.javeriana.edu.co/index.php/vnijuri/article/view/14666

Piero Calamandrei, Crisis de la justicia, en La crisis del derecho, 301-335 (Georges Ripert ed., Ed. Jurídicas Europa América, 1961).

\section{Notas}

* Artículo de investigación

[1] José Castán, Crisis mundial y crisis del derecho, Editorial Reus, 11 (1961).

[2] Jacques Derrida, La deconstrucción en las fronteras de la filosofía, Ed. Paidós,13-22 (1989).

[3] En la introducción del texto se dice de la idea de deconstrucción, que está actualmente desautoriza, deconstruye teórica y prácticamente los axiomas hermenéuticos usuales de la identidad. Así, este pensamiento no puede descansar en una unidad consigo mismo. Tiene que aplicarse aquella inestabilidad que el mismo término produce a la sonámbula seguridad metódica de la historia convencional de las ideas, al poner en cuestión las nociones tradicionales de génesis, sistema, método, desarrollo, evolución, influencias e interpretaciones. Vid., in extenso, Jacques Derrida, op. cit., 15.

[4] Jordi Pueyo, Entrevista a Antonio Marcianò. El físico que reivindica el Renacimiento: "Ser expertos en una sola cosa nos hace estúpidos”. El País. 14 de junio de 2019. En un alegato a la interdisciplinariedad, Marcianò evoca al conocimiento transversal del Renacimiento: ser expertos en una sola cosa nos hace estúpidos, así no puede haber progreso; señala este físico italiano en esta entrevista.

[5] José Castán, op. cit., 12.

[6] Luis Diez-Picazo y Ponce de León, Contrato y Libertad Contractual, THĒMIS-Revista de Derecho, n. ${ }^{\circ}$ 49, 7-14 (2004).

[7] Carlos Andrés Uribe Piedrahita, Los compromisos - settlements - en América Latina y las consecuencias sobre la aplicación privada del derecho de la competencia. Un camino por replantear, en La aplicación privada del Derecho de la Competencia, 803-818 (Luis Antonio Velasco San Pedro et. al. eds., 2011).

[8] Giacomo Delitala, La crisis del derecho en la sociedad contemporánea, en La crisis del derecho, 153-182 (Georges Ripert ed., Ed. Jurídicas Europa América, 1961). Agrega que con ello no pretende afirmar en lo más mínimo que aquella concepción del Estado no fuese otra cosa que una ficción o, peor aún, una mentira hipócrita. Vid., in extenso, Giacomo Delitala, op. cit., 156.

[9] Íd. 
[10] Arturo Jemolo, La crisis del Estado moderno, en La crisis del derecho, 183-265 (Georges Ripert ed., Ed. Jurídicas Europa América, 1961). Jemolo agrega que esa crisis de las instituciones se ha caracterizado siempre por un cambio en las normas vigentes, sobre todo en el ámbito del derecho público, y muy a menudo se ha de revelar por la falta de aplicación de las normas vigentes y por la sustitución de las mismas por otras normas no escritas. Vid., in extenso, Arturo Jemolo, op. cit., 186-187.

[11] Balladore fundamenta además que el racionalismo liberal del siglo XIX se había preocupado de muchas cosas a propósito del Estado. Solo una había descuidado casi por completo, como es conocidísimo: la eficiencia del propio Estado. Vid., in extenso, Giorgio Balladore, La crisis de la personalidad del Estado, en La crisis del derecho, 288 (Georges Ripert ed., Ed. Jurídicas Europa América, 1961). Y en cuanto a la crítica al Estado, señala el autor que "debemos reconocer abiertamente que las viejas posiciones son insostenibles. El principio de la personalidad del Estado con su requerimiento, tan elevado, a la legalidad, ha demostrado en su desarrollo los peligros con que podía tropezar; elevada la legalidad a un fin en sí mismo ha dado origen a toda una superflua maraña de normas, de vínculos, de limitaciones, que solo cumplen la función negativa de trabar la acción. A menudo se habla de crisis del derecho, no sé qué parte corresponde a una transitoria crisis de valor perenne del derecho, y qué parte corresponde a una saludable reacción un estéril y hoy excesivo legalismo" Giorgio Balladore, op. cit., 267-297.

[12] Calamandrei subraya, respecto de la autonomía de la justicia, que esto es separado de la política u otros factores como la moral, que la separación entre justicia y política es posible en los períodos estáticos de la vida social, en aquellos períodos de ritmo lento, de aparente inmovilidad de las instituciones y de las leyes que las regulan. Cuando las leyes vigentes son producto de una política aceptada por la mayoría, las mismas resultan respetadas por la conciencia social como expresión de justicia, son periodos de pacífica legalidad en el que parece haberse alcanzado el ideal de justicia. En estos periodos la distancia entre el ius conditum (el derecho establecido) y el ius condendum (el derecho que debe ser establecido), entre la realidad y el ideal del derecho, parece mínima; y el juez puede ser un puro lógico. Pero existen otros periodos en que esta distancia se alarga hasta provocar su fractura: la divergencia entre las leyes como son y las leyes como se querría que fuesen se acrecienta. Las viejas leyes siguen en pie, pero las corrientes políticas de que surgieron están superadas, y apremian nuevas exigencias sociales. Estos son los periodos de crisis de la legalidad: cuando el juez se ve constreñido a aplicar leyes que ya no corresponden a la conciencia social. Piero Calamandrei, Crisis de la justicia, en La crisis del derecho, 314-315 (Georges Ripert ed., Ed. Jurídicas Europa América, 1961).

[13] José Castán, op. cit., 24.

[14] Luis Diez-Picazo y Ponce de León, op., cit., 9.

[15] Carnelutti, cáustico crítico de la evolución del derecho, hace un balance después de haber hablado tanto de la crisis del derecho, argumenta que "hace tiempo que el derecho ha venido perdiendo poco a poco, cada vez más, su doble función de certeza y de justicia”, señalando que si "al riesgo en dirección de la justicia no corresponde una garantía de justicia, o al riesgo en dirección de la justicia, una garantía de certeza, entonces se sale de la fisiología para entrar en la patología del derecho” o muerte del derecho. Examina el autor la motorización legislativa como causa de crisis de certeza y crisis de justicia, "la multiplicación de las leyes jurídicas, semejante a la multiplicación de las leyes naturales, hace de modo que el ciudadano, que, para observarlas debería conocerlas, ya no está en condiciones de hacerlo. La publicación de las mismas, como condición de su imperatividad, ha cambiado de carácter, de presunción, convirtiéndose en ficción. El hombre de la calle entre el fárrago de las leyes, anda cada vez más desorientado, al igual que el conductor de un vehículo cuando demasiados faros se entrecruzan a lo largo de la ruta. La creciente velocidad de la vida social no puede dejar de repercutir sobre la vida de las leyes. Las leyes no consiguen llegar ya a la vejez. Como la belleza de una música la bondad de una ley no depende solo de quien la compone sino de quien la ejecuta” Francesco Carnelutti, La muerte del derecho, en La crisis del derecho, 339-362 (Georges Ripert ed., Ed. Jurídicas Europa América, 1961). Para concluir en la muerte del derecho, argumenta que "igualmente conocida en sus causas como en sus efectos es la crisis judicial. Demasiados procesos civiles y penales, contenciosos y voluntarios. La cantidad de procesos como la cantidad de leyes no puede dejar de influir sobre su calidad. Lo mismo que el legislador, tampoco el juez tiene ya paz" (Francesco Carnelutti, op. cit., 347). El autor, concluyente, alude a un discurso de un jurista en el sentido que aquél "inauguraba un discurso con una de las frases más sombrías del evangelio: tristis est anima mea usque ad mortem (mi alma está triste al extremo de la muerte). Tenía el tono de un discurso fúnebre: era conmemorando el proceso; pero el derecho no puede vivir sin el proceso, como no puede vivir un hombre sin el corazón. Escuchando aquel lamento el público se dividió: a la mayoría le pareció una exageración pesimista y una minoría quedó impresionada. Este hombre decía la verdad. Se le puede achacar un error: el haber concluido con una duda antes que una certeza. El proceso, antes bien, el derecho, si no está muerto, morirá. Pero solo porque ya no tienen en el corazón una sola gota de esperanza los hombres. Cuando uno muere visten de duelo. Si en ellos la flor de la esperanza abriese su cáliz, sabrían que la vida no es un ir hacia la muerte, sino la muerte un ir hacia la vida. Con el derecho sucede lo mismo". Vid., in extenso, Francesco Carnelutti, op. cit., 346 y ss.

[16] Juan Blanch, Algunas reflexiones en torno al concepto romano y moderno de contrato, CEU Ediciones (2017).

[17] Juan Blanch, op. cit., 8. 
[18] La Instituta de Gayo, Descubierta recientemente en un palimpsecto de la Biblioteca Capitular de Verona, traducida por primera vez al castellano (1845). El texto original (libro tercero, fragmento 88) aparece en el siguiente sentido: Nunc transeamus ad obligationes, quarum summa divisio in duas species deducitur, omnis enim obligatio uel ex contractu nascitur, uel ex delito. $Y$ su traducción: Pasemos ahora a las obligaciones, cuya principal división se reduce a dos especies, pues que toda obligación o nace de un contrato o procede de un delito.

[19] Gai, Res cottidianae, en Antonio Silva Sánchez, Origen del concepto actual de contrato en el marco del derecho privado comparado. Situaciones especiales del contrato de arrendamiento (locatio conductio) en el derecho romano y en el derecho privado comparado, Ars Iuris, n. ${ }^{\circ}$ 39, 181 (2008). El autor refiriéndose a Gayo en la Res cottidianae, y luego de la redacción del texto gayano, señala que "se infiere con claridad que los acuerdos de voluntades y los actos ilícitos eran fuente notoriamente insuficiente ya para los juristas de su tiempo. En efecto, la identificación de contractus con acuerdo, dejaba de lado una gran cantidad de actos lícitos que engendraban una obligatio y que no encajaban en la summa divisio de Gayo, por ejemplo, el pago de lo indebido (solutio indebiti) que generaba, en quien lo recibió, la obligación de devolverlo"; vid, in extenso, Antonio Silva Sánchez, op. cit., 182.

[20] Íd., D. 44.7.1 pr. (El subrayado es nuestro)

[21] Juan Blanch, op. cit., 9.

[22] Un mayor examen en cuanto a la solutio indebiti, vid., Adolfo Wegmann Stockebrand, En torno al carácter (cuasi) contractual de la solutio indebiti en las Instituciones de Gayo, Revista Estudios Histórico-Jurídicos, n. ${ }^{\circ}$ 39, 85-110 (2017).

[23] Ulpiano, en Alejandro Guzmán Brito, Causa del contrato y causa de la obligación en la dogmática de los juristas romanos, medievales y modernos y en la codificación europea y americana, Revista Estudios Histórico-Jurídicos, n. ${ }^{\circ}$ 23, 209-367 (2001). Guzmán Brito agrega que de acuerdo con esto "el concepto supremo interesante es el de convención (del derecho de gentes). El pacto ocupa un lugar subordinado en el esquema. Sin embargo, los medievales partieron no de la convención sino del pacto”; vid, in extenso, Alejandro Guzmán Brito, op. cit., 271.

[24] Jurista destacado del siglo I d. C.

[25] Ulpiano, en Alejandro Guzmán Brito, op. cit., D. 2 14. 3.

[26] Juan Blanch, op. cit., 13.

[27] Código Civil Francés [CCFr]. Ley del 21 de marzo de 1804. Art. 1100. 21 de marzo de 1804 (Francia)

[28] Jorge López Santamaría, Los contratos: parte general, Ed. Jurídica de Chile, 32 (1986).

[29] Luis Diez-Picazo y Ponce de León, op., cit., 10.

[30] Íd.

[31] Código Civil Colombiano [CCC]. Ley 57 de 1887. Arts. 1602. 15 de abril de 1887 (Colombia).

[32] Jaime Arrubla Paucar, Contratos mercantiles, Ed. Legis (3a ed., 1986)

[33] Ley 1480 de 2011. Por medio de la cual se expide el Estatuto del Consumidor y se dictan otras disposiciones. 12 de octubre de 2011. D.O. n. ${ }^{\circ}$ 48.220. (cfr. arts. 1 y 42).

[34] Luis Diez-Picazo y Ponce de León, op., cit., 11.

[35] Encarnación Fernández Ruiz-Gálvez, Rebus sic stantibus y crisis económica. Orden público económico versus especulación, XXXIII Anuario de Filosofía del Derecho, 67 (2017).

[36] Luis Clavería, La progresiva degradación de nuestro ordenamiento en materia de cláusulas contractuales abusivas, Revista Aranzadi Doctrinal, n. ${ }^{\circ}$ 2, 30 (2014).

[37] Luis Diez-Picazo y Ponce de León, op., cit., 12.

[38] Luis Clavería, op., cit., 30. Aunque aún yace en la atmósfera de la comunidad académica que la legitimación del contrato de adhesión no ha superado aún el terreno dogmático, no se puede decir lo mismo del ámbito funcional o empírico que tiene en el mercado.

[39] Cfr. arts. 42 y 43 de la Ley 1480 de 2011. 
[40] Corte Suprema de Justicia, Sala de Casación Civil, Sentencia aprobada según acta n. ${ }^{\circ} 112$ de $1^{\circ}$ de diciembre de 1970. Gaceta Judicial, Tomo CXXXVI. (M. P. Dr. Guillermo Ospina Fernández; 15 de diciembre de 1970); Corte Suprema de Justicia, Sala de Casación Civil. Sentencia aprobada según Gaceta Judicial, Tomo CLXVI, Número 2407. (M. P. Humberto Marcia Ballén; 29 de agosto de 1980).

[41] Luis Diez-Picazo y Ponce de León, op., cit., 13.

[42] Código Civil Colombiano [CCC]. Ley 57 de 1887. Art. 1508. 15 de abril de 1887 (Colombia).

[43] Luis Diez-Picazo y Ponce de León, op., cit., 13.

[44] Comisión de Derecho Europeo de los Contratos, Principios Europeos de Derecho de Contratos, PECL (2000). Art. 2101

[45] Íd. Art. 2102

[46] Mariana Bernal, La transformación de la causa en el derecho de contratos francés, 55 Vniversitas, n. $.^{\circ} 111,241$ (2006). Agrega la autora que el derecho francés, pese a los esfuerzos de renovación, se rehusa a abandonar la noción de causa en su legislación.

[47] Acerca de la problemática jurídica que genera la subrogación de la maternidad, vid., in extenso, Juan Cruz \& Laura Castro, La omisión legislativa en materia de contrato de alquiler de vientre materno en Colombia y consecuencias jurídicas, 6 Revista Criterio Jurídico Garantista, n. ${ }^{\circ}$ 11, 110-125 (2014). Véase también lo descrito por la sentencia C-807 de 2002 que señala "que con los avances de la ciencia y tecnología es posible llegar no solo a la exclusión de la paternidad, sino, inclusive, a la atribución de ella, estableciendo con un alto grado de probabilidad que el presunto padre lo es realmente respecto del hijo que se le imputa. El avance de la ciencia y tecnología han convertido en obsoletas muchas de nuestras leyes y nuestros códigos, en especial nuestro código civil”. Corte Constitucional de Colombia. Sentencia C-807 de 2002 (M. P. Jaime Araujo Rentería; 3 de octubre de 2002).

[48] Sobre este particular, vid., Javier Ibáñez, Blockchain: Primeras cuestiones en el ordenamiento español, Ed. Dykinson, 146 (2018), en el que, entre otras cosas, el autor señala que el impacto de la tecnología blockchain entraña una revolución de alcance incluso mayor del que supuso hace dos décadas la irrupción de internet. Y respeto de la contratación, las partes pueden pactar en el espacio de una blockchain infinidad de modelos de negociación y de contenidos contractuales, a través de aplicaciones descentralizadas (DApps). Incuestionablemente, blockchain, en cuanto espacio descentralizado facilitador de la contratación electrónica desde los nodos, es un mecanismo democratizador, tanto de las inversiones (financieras o no financieras) como del comercio en general.

[49] Beatriz Romero Flores, Las neurociencias frente a la función de la pena, LXVIII Anuario de Derecho Penal y Ciencias Penales, n. ${ }^{\circ} 1,335-357$ (2015).

[50] Giacomo Delitala, op. cit., 163.

[51] Francesco Carnelutti, op. cit., 346 y ss. In extenso, vid., Supra, III.

[52] Georges Ripert, Evolución y progreso del derecho, en La crisis del derecho, 13-31 (Georges Ripert ed., Ed. Jurídicas Europa América, 1961). El autor señala que las fuerzas que actúan sobre la evolución del derecho son, por un lado, las fuerzas conservadoras, las cuales ejercen a favor del mantenimiento del orden jurídico existente y, de otro lado, están las fuerzas reivindicadoras, que cuando triunfan son creadoras de nuevo derecho. Vid., Georges Ripert, op. cit., 18-24.

[53] Adolfo Ravà, Crisis del derecho y crisis mundial, en La crisis del derecho, 101-151 (Georges Ripert ed., Ed. Jurídicas Europa América, 1961). El autor agrega que la historia del derecho, por otra parte, nos revela un alternarse de periodos orgánicos y periodos críticos, pero nos enseña que las diversas crisis del derecho han estado siempre conectadas a grandes crisis históricas, que implican todos los aspectos de la vida colectiva. Vid., Adolfo Ravà, op. cit., 114-115.

[54] Adolfo Ravà, op. cit., 128-131.

[55] Arturo Jemolo, op. cit., 264.

[56] Georges Ripert, op. cit., 30.

[57] Giacomo Delitala, op. cit., 162 y ss.

[58] Giacomo Delitala, op. cit., 164.

[59] Giacomo Delitala, op. cit., 165. 
[60] Piero Calamandrei, op. cit., 315.

[61] Piero Calamandrei, op. cit., 335. Además, argumenta el autor que el derecho no muere; mueren los hombres, mueren los juristas, mueren también los magistrados (aunque en Norte América se acostumbra decir que los magistrados de la Corte Suprema no dimiten nunca y mueren muy raramente), pero el derecho, esa fuerza en continua búsqueda de perfección, no muere.

[62] Adolfo Ravà, op. cit., 132.

[63] Íd.

[64] Francesco Carnelutti, op. cit., 339.

[65] Álvaro d'Ors, Derecho y sentido común: siete lecciones de derecho natural como límite del derecho positivo, Ed. Cuadernos Civitas (3a. ed., 2001).

[66] In extenso, vid., Giacomo Delitala, op. cit., 160-162.

\section{Licencia Creative Commons CC BY 4.0}

Para citar este articulo/To cite this article: John Alberto Tito Añamuro, El ocaso del contrato: Un estudio desde la doctrina contractual clásica. Problemas en torno a su eficacia, 68 Vniversitas, n. ${ }^{\circ} 139$ (2019). https://doi.o $\mathrm{rg} / 10.11144 / J a v e r i a n a . v j 139 . e o d c$ 